\title{
Just listen!
}

\section{Hamish Robert Osborne}

Welcome to the Australasian College of Sport and Exercise Physicians edition of the BJSM.

In the first minute of a consultation, if you stay quiet, your patients will tell you where they hurt, how it started and be quite happy that you actually listened to them. However, this doesn't tell you why they are sore and why they got injured. It's our job to delve deeper to determine not just some, but all of the risk factors that lead to injury. Without doing so, your patient is at risk of a poor recovery or recurrent injury. During the recovery/rehabilitation phase, patients will also tell you why they are having trouble with the process, if you are prepared to listen-many will tell you what you want to hear rather than what is actually troubling them. Articles in this month's edition highlight some of these issues.

Timpka et al show us that sexual and physical abuse is associated with higher rates of sport-related and non-sport-related injuries (see page 1412). For some of these people, their injury may be the vehicle for them to finally receive help for the past wrongdoings to them. Like any other risk factor, we need to try to identify it and address it. Identifying risk factors takes skill and trusting relationships.

Burns et al describe the key components in developing strong interpersonal relationships in high-performance sport (see page 1386). These elements are important in dealing with stress and drivers of performance-all-important in many of our patients lives.

McCradden and Cusimano listened to many survivors' stories, people who suffered a lifetime of harm from within a broken sports medicine system (see page 1384). They shed light on a way forward-listening and acting.

Correspondence to Dr Hamish Robert Osborne, Medicine, University of Otago, Dunedin 9016, New Zealand; hamish.osborne@otago.ac.nz
Sometimes new information comes to hand quickly and requires swift coordinated intervention to change the course of an injury risk profile. Blauwet et al describe timely and effective intervention in sport resulting in a great outcome for athletes and sport in general (see page 1390).

O'Keeffe et al put listening as their number one thing to do when educating a patient about their back pain (see page 1385).

Gardner et al performed a rare thing in Sport and Exercise Medicine-a randomised controlled trial of exercise intervention in low back pain (see page 1424). They too listened to their patients and let their patients guide their treatment.

The common theme coming through in this selection is the importance of listening. Our patients are always trying to tell us something, if it's important to them, it should be important to us. We should also listen to the literature-someone asked me recently what is new in Sport and Exercise Medicine-my answer was easy, there is a list of things we should just stop doing, a far longer list than what is new and actually works! We should listen to our patients and the literature and be brave and act.

The Australasian College of Sport and Exercise Physicians warmly welcome you to attend the 2020 Annual Scientific Conference in Canberra, Australia, from 05 to 07 February. Canberra is Australia's capital city and is built around the beautiful Lake Burley Griffin (shown on the cover page), the scene of the fun run which is part of the physical activity morning to kick the conference off. We have a great faculty of speakers including Dr Tracy Ray, Director of the Primary Care Sports Medicine Fellowship programme at Duke University, and Dr Jane Thornton, Medical and Scientific Expert for the International Olympic Committee's Active Well-being Initiative and recipient of the 2015 AthletesCAN Social Responsibility
Award for her contribution to society by sport/volunteer initiatives.

On behalf of the Australasian College of Sport and Exercise Physicians, I hope you enjoy this month's edition of the British Journal of Sports Medicine and I hope to see you Down Under in 2020 in Canberra.

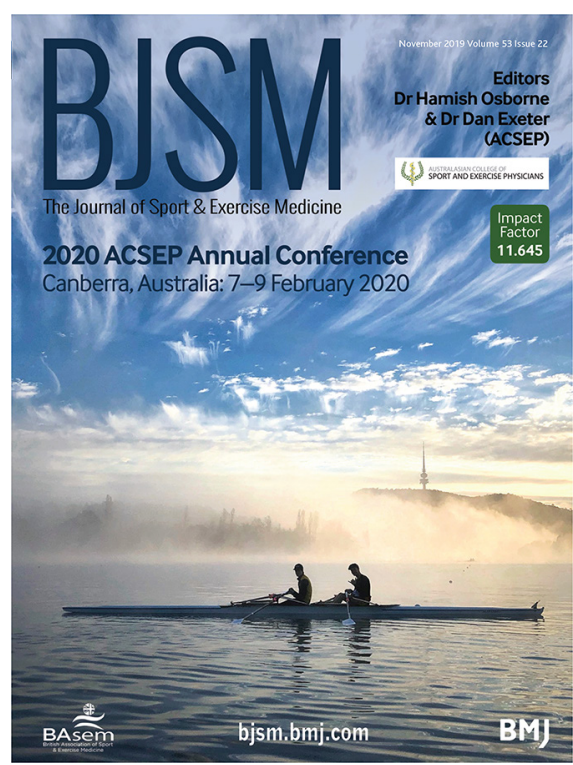

Twitter Hamish Robert Osborne @Hamish_Osborne

Funding The author has not declared a specific grant for this research from any funding agency in the public, commercial or not-for-profit sectors.

Competing interests None declared.

Patient consent for publication Not required.

Provenance and peer review Commissioned: internally peer reviewed.

(C) Author(s) (or their employer(s)) 2019. No commercial re-use. See rights and permissions. Published by BMJ.

$$
\text { D Check for updates }
$$

To cite Osborne HR. Br J Sports Med 2019;53:1383.

Accepted 18 September 2019

Br J Sports Med 2019;53:1383

doi:10.1136/bjsports-2019-101539

\section{ORCID iD}

Hamish Robert Osborne http://orcid.org/0000-00024265-4833 